\title{
PROFILE OF OPEN GLOBE INJURY IN CHILDREN AT LUMBINI EYE INSTITUTE
}

\author{
Binita Bhattarai ${ }^{1}$, Santosh Pokhrel $^{1}$, Bel Thapa ${ }^{2}$ Prachand Gautam ${ }^{3}$, Nanda Gurung ${ }^{4}$
}

\begin{abstract}
INTRODUCTION: Ocular trauma is preventable public health problem throughout the world that especially affects the young. During the last several decades the prognosis of open-globe injuries has significantly improved. The aim of this study was to describe the clinical profile of open globe injury in children and visual outcome after surgery.

MATERIAL AND METHODS: It is a prospective hospital based study that included children aged 1-15 yrs presenting to Lumbini Eye Institute (LEI), Bhairahawa with open globe injury. Visual acuity and Anterior and Posterior Segment examination findings were recorded at the time of presentation, after surgery and in three subsequent follow up visits.

RESULTS: Out of 26,538 pediatric patients, during the study period $0.26 \%(n=69)$ had open globe injury. The most common age group was 510 years comprising $43.5 \%$, with a strong male preponderance of $74 \%$ and mean age of $8.06 \pm 3$.6years. Playing was the most common mode of injury comprising $58 \%$, where as stick was the most common agent causing trauma consisting 51\%. Fifty two percent were visually impaired and 39\% were blind at the time of presentation and only $9 \%$ children had visual acuity better than $6 / 18$. Improved vision was found in $52 \%$, same vision in $34 \%$ and deteriorated vision in $13 \%$ till third follow up visit. Anatomical integrity of the globe was maintained in $88.4 \%$ and only $11.6 \%$ had Phthisis bulbi.
\end{abstract}

CONCLUSION: The incidence of open globe injury among children at Lumbini Eye Institute was $0.26 \%$. Male children were more vulnerable. Stick was the most common traumatizing agent. There was a favorable outcome with improved vision in most children after surgery.

KEYWORDS: Ocular trauma; Open globe injury; Pediatrics eye injury

1. Ophthalmologist, Lumbini Eye Institute, Bhairahawa, Nepal

2. Pediatrician, Siddhartha children and women Hospital, Butwal, Nepal

3. Glaucoma specialist, Lumbini Eye Institute, Bhairahawa, Nepal

4. Glaucoma Consultant, Lumbini Eye Institute, Bhairahawa, Nepal

\author{
For Correspondence: \\ Dr. Binita Bhattarai, MD \\ Ophthalmologist, \\ Lumbini Eye Institute, \\ Bhairahawa, Nepal \\ E-mail: bhattaraibinita@hotmail.com
}




\section{INTRODUCTION}

Ocular trauma is an important cause of visual impairment worldwide. It is estimated that more than 2 million people suffer from ocular trauma annually and 40,000 become visually handicapped permanently. ${ }^{1}$ A national survey conducted in 1981 has shown blindness due to ocular trauma to be $2.4 \%{ }^{2}$

Ocular trauma is a leading cause of severe anatomic and functional impairment of the visual system. ${ }^{1}$ Eye injuries affect mostly the children and often tends to be open globe type. The greatest number of eye injury occurs during playtime, primarily attributable to fall and to free projectile hitting the globe at high frequency. ${ }^{3}$ Children's eyes are particularly at stake in injuries because of their reduced ability to avoid or detect dangers. ${ }^{4}$ During the last several decades, the prognosis for patients with open-globe injuries has significantly improved. This has been attributed to the advent of enhanced micro surgical techniques and instrumentation, along with an improved understanding of pathophysiologic mechanisms of ocular trauma. ${ }^{5}$ However, little is known about the demographic profile and outcome of surgery in children with open globe injuries. Thus, this study was carried out to describe the clinical profile of open globe injury in children and the visual and anatomical outcome after surgery.

\section{MATERIAL AND METHODS}

This is a prospective hospital based study including patients below 16 years of ageand diagnosed as open globe injury who presented to Lumbini Eye Institute (LEI) from January 2012 $\mathrm{AD}$ to December $2012 \mathrm{AD}$ and provided informed written consent for enrollment in the study. Patients' age, gender, laterality of the eye affected, object causing injury, duration between trauma and primary intervention, visual acuity, zone of injury and detailed examination of the anterior and posterior segment were recorded at the time of presentation and 3 follow up visits after surgery. Treatment was carried out as per the hospital protocol. First follow up was at 1 week after the day of discharge and second follow up was after 2 weeks from the day of first follow up. The Third follow up was after 8 weeks from the day of second follow up. Patient data were entered and the result analysis was done using SPSS 16.1.

\section{RESULTS}

Out of 26,538 pediatric patients, $0.26 \%(n=69)$ had open globe injury. Among them (51) 74\% were male and (18) $26 \%$ were female. The mean age of the children was $8.06 \pm 3.6$ years. The most common age group to sustain open globe injury was 5-10 years comprising $30(43 \%)$ followed by $0-5$ years $20(29 \%)$. (Table 1)

Table 1: Age distribution of children with open globe injury

\begin{tabular}{|l|l|}
\hline Age range(years) & Frequency (\%) \\
\hline$</=5$ & $20(29 \%)$ \\
\hline$>5-10$ & $30(43 \%)$ \\
\hline$>10$ & $19(28 \%)$ \\
\hline Total & $\mathrm{N}=69(100 \%)$ \\
\hline
\end{tabular}

Fifty eight percent (40) of the children sustained open globe injury during playing, followed by accidental injuries comprising $42 \%$ (29). Stick was the most common traumatizing object with prevalence of $51 \%$ (35), followed by iron $10 \%$ (7) and glasses $7 \%$ ( 5). Thirty five percent (24) children only presented within 24 hours after injury whereas $54 \%$ (37) presented between 24 hours to 7 days and 11\% (8) presented after a week of injury.

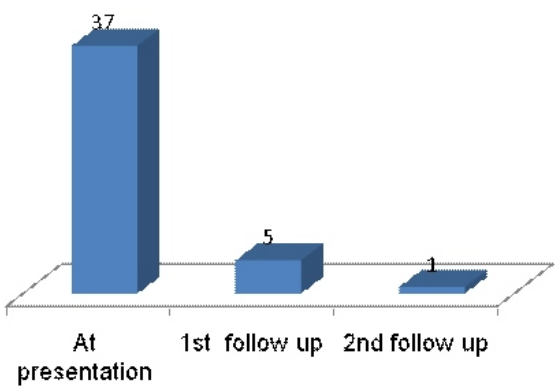

Figure 1: Development of traumatic cataract at different times

Traumatic cataract was present in 54\% (37) during initial presentation and 7\% (5) during $1^{\text {st }}$ follow up (Figure 1).

Table 2: Status of visual acuity at the time of discharge

\begin{tabular}{|l|l|}
\hline Visual Acuity & Frequency $\mathbf{n = 6 9 ( \% )}$ \\
\hline Improved & $36(52 \%)$ \\
\hline Same & $24(35 \%)$ \\
\hline Detoriated & $9(13 \%)$ \\
\hline Total & $69(100 \%)$ \\
\hline
\end{tabular}


Fifty two percent (36) had improved visual acuity, 35\% (24) had same visual acuity and $13 \%(9)$ had deteriorated vision at the time of discharge. Ninety two percent (63) had visual acuity of $<3 / 60 \mathrm{PL}$ at the time of presentation whereas at the time of discharge only $23 \%$ (16) had this visual acuity. Visual acuity $(6 / 18-6 / 60)$ was present in only $1 \%$ at the time of presentation and this was improved to $19 \%$ at the third follow up. On $3^{\text {rd }}$ follow up, $61(88 \%)$ cases had normal anatomical appearance maintained and $8(12 \%)$ had undergone phthisis of the eye. (Table 3 )

\section{Table 3: Visual acuity at presentation and third followup}

\begin{tabular}{|l|l|l|}
\hline $\begin{array}{l}\text { Visual acuity } \\
\text { category }\end{array}$ & $\begin{array}{l}\text { At presentation } \\
\%(\mathbf{n = 6 9 )}\end{array}$ & $\begin{array}{l}\text { At 3rd follow up } \\
\mathbf{\%}(\mathbf{n}=\mathbf{6 9})\end{array}$ \\
\hline $6 / 6-6 / 18$ & $0 \%$ & $9 \%(6)$ \\
\hline$<6 / 18-6 / 60$ & $1 \%(1)$ & $19 \%(13)$ \\
\hline$<6 / 60-3 / 60$ & $6 \%(4)$ & $33 \%(23)$ \\
\hline$<3 / 60-\mathrm{PL}$ & $92 \%(63)$ & $23 \%(16)$ \\
\hline NPL & $1 \%(1)$ & $16 \%(11)$ \\
\hline Total & $100 \%(69)$ & $100 \%(69)$ \\
\hline
\end{tabular}

\section{DISCUSSION}

Ocular injury is an important cause of ocular morbidity in children; being a leading cause of non congenital unilateral blindness in this age group. ${ }^{6}$ Most ocular injuries in children are preventable, particularly those by sports. These types of injuries are not common but when they do occur they tend to be more serious and frequently require surgical intervention. In our study, it was observed the age specific pattern of ocular injury with higher prevalence in the age group of $5-10$ years (43.5\%), which was similar to Dulal S (38.1\%) ${ }^{7}$ and Saxena R et al. $(87.7 \%)^{8}$. The age group $5-10$ years was most vulnerable to ocular injury as these age groups are relatively immature but more active and are exposed to varying surroundings leading to injuries. Male predominance was seen in our study that was $74 \%$ which was similar to Malik A et al. $(77.5 \%)^{9}$, VK Gothwal, S.Adolph, TJ Naduvilath $(86.6 \%)^{10}$ and Dulal S et al. $(62 \%))^{7}$ The reason for this can be explained to the adventurous and aggressive nature of boys.

Regarding the different modes of trauma, our study showed the maximum number of injury were related with playing, accounting $40(58 \%)$ which is similar to Mc Grieshaber and R Stegmann ${ }^{11}$ who found around $66 \%$ injuries during play.
The most common traumatizing agent was stick which accounted for $51 \%$ cases. Children get injured themselves by wood or stick as our part of the world is basically dependent on agriculture and people belong to low socioeconomic group. Children do work to help their parents which include collecting the woods, cutting the wood into pieces for cooking. The other reason is that, they don't have expensive toys to play with so they play with the stick either in the form of Bow and arrow or any other form finally getting injured by them. Similar to our study Abebe Bejiga found wood to be most common $67(32.8 \%)^{12}$.

Open globe injuries are one of the marked reasons for acute and long-standing visual loss in children and young adults. Visual acuity was found to be improved in 36(52.17\%), visual acuity remained same in $34.78 \%$ and further detreated in $13.04 \%$.In a study done by Saxena et al. ${ }^{7} 15 \%$ attained visual acuity of better then $6 / 12$. The finding in this study was close to our finding that was $9 \%$. In another study by Silveria $\mathrm{S}$, the final visual acuity was $6 / 12$ or better in $36 \%$ of children and $<6 / 60$ in $31 \%$. $^{13}$

The strength of this study is that it describes a cohort of children with open globe injury which is a serious form of ocular trauma that may lead to permanent blindness. The outcome after surgery is followed till third follow up including visual and anatomical outcome.

The limitation is that convenient sample size was taken that included children presented within one year duration only. Seasonal variation of the children presenting with injuries were not analyzed.

\section{CONCLUSION}

Open globe injuries are one of the major causes of monocular blindness and more common in the age group 5-10 years with the incidence of $0.26 \%$. Males are more vulnerable to open globe injury during playing. There was a favorable outcome with improved vision in most children after surgery.

\section{REFERENCES}

1. www.who.int/mediacentre/factsheets/fs282/en/ Visual Impairment and Blindness. Assessed on 15th June 2014.

2. National Survey on Blindness and Eye disease in nepal by $H M G$, WHO/PBL, 1981. Available on www.who.int/ncd/ vision2020 actionplan/documents. Assessed on 15th April 2013.

3. Pazzo SD, Pensiero S, Paolo Perissutti. Ocular Injuries By Elastic Cords In Children. Pedriatrics 2000 Nov; 106(5): 65-69. http://dx.doi.org/10.1542/peds.106.5.e65 
4. Brilliant GE, Pokhrel RP, Graseet NC, Brilliant LB. The Epidemiology of blindness in Nepal. A report of the 1981 Nepal Blindness Survey, the Seva Foundation. Chelsea, 1988.

5. L.O. Onyekwe. Eye Injuries InChildrens. The Nigerian Journal Of Surgical Research, 2001 Dec, Vol.3:3-4.

6. Pieramici DJ, Sternberg P, Aaberg TM. A system for classifying mechanical injuries of the eye (globe). Am J Ophthal 1977; 123: 820-31.

http://dx.doi.org/10.1016/S0002-9394(14)71132-8

7. Dulal S, Ale JB, Sapkota YD. Profile of Pediatric Ocular Trauma in mid western hilly region of Nepal. Nepal J Ophthalmol 2012 Jan-Jun; 4(7): 134-7.PMid:22344011

8. Saxena R, Sinha R, Purohit A, Dada T, Vajpayee RB, AZa RV. Pattern of pediatric ocular trauma in India. Indian $J$ Pediatr. 2002 Oct, 69(10): 863-7.

http://dx.doi.org/10.1007/BF02723708PMid:12450295
9. Malik A, Bhala S, Arya SK, Sood S, Narang S. Five year study of ocular injuries due to fireworks in India, IntOpthalmology, 2013 $\operatorname{aug}(4): 381-5$

10. Gothwal VK, Adolph S,JalaliS,Naduvilath JJ. Australian and New Zealand Journal of Opthalmology, 1999, 27, 318-25. http://dx.doi.org/10.1046/j.1440-1606.1999.00225.x PMid: 10571392

11. Grieshaber Mc, Stegmann. Penetrating eye Injuries in South African Children: Aetiology and visual outcome. Eye. 2006, 20, 789-95.

http://dx.doi.org/10.1038/sj.eye.6702003PMid:15999122

12. Bejiga A. Causes and Visual Outcomes of Perforating Ocular Injuries among Ethiopian Patients. Community Eye Health Journal 2001; 14: 39, 45-6.

13. Silveira S, Thompson P. Pediatric Ocular Injury: A Review Of Literature, page (7:)1-15. 